\title{
The sigmoidoscope: Used too much or too little?
}

\author{
Eric Semlacher MD FRCPC
}

\section{ARTICLE}

Van Rosendaal GMA, Sutherland LR, Verhoef MJ, et al. Defining the role of fiberoptic sigmoidoscopy in the investigation of patients presenting with bright red rectal bleeding. American Journal of Gastroenterology 2000;95(5):1184-7.

$\mathrm{T}$ his is one of several reports generated from data collected for the Alberta Endoscopy Project, a joint undertaking of the University of Calgary and the University of Alberta. The Alberta Endoscopy Project prospectively collected records in a computer database on all inpatient and outpatient endoscopic procedures performed at four of Alberta's major teaching hospitals during the mid-1990s. In this particular report, Van Rosendaal et al summarized the results of all colonoscopy examinations done for rectal bleeding at the Calgary General Hospital between June 1995 and February 1996. A total of 143 patients had sufficient data collected to be included in the report. It appears that most of the rectal bleeding episodes were fairly modest, although this is only inferred from comments made in the paper's discussion and conclusions. In $62 \%$ of patients, the bleeding lesion was thought to be located in the distal $20 \mathrm{~cm}$, a further $16 \%$ in the region from 20 to $60 \mathrm{~cm}$ from the anus, and only $8 \%$ above the level of $60 \mathrm{~cm}$ from the anus. In the subset of patients younger than 55 years of age, the bleeding lesion was identified in the distal $20 \mathrm{~cm}$ in 41 of 61 $(67 \%)$, between 20 and $60 \mathrm{~cm}$ in seven of $61(11 \%)$, and beyond $60 \mathrm{~cm}$ in three of $61(5 \%)$. It seems that there were several instances where the location of bleeding was not identified.

This paper emphasized that minor rectal bleeding is most often caused by a lesion that is within the reach, theoretically, of a sigmoidoscope and that additional findings at colonoscopy are probably incidental rather than the cause of the presentation of rectal bleeding. The authors criticized the fairly com- mon practice of proceeding to colonoscopy in most cases of rectal bleeding, which they thought put an undue burden on already limited resources. They concluded that patients younger than age 55 years who pass small amounts of fresh blood per rectum may be adequately investigated using fiberoptic sigmoidoscopy alone, initially at least. The paper does have weaknesses. While acknowledging potential criticisms of the limitations of their own data and methodology, van Rosendaal et al reviewed the literature supporting the conclusions that they have drawn.

An accompanying editorial in the same issue of the American Journal of Gastroenterology by Douglas K Rex rightly sets the paper's conclusions into better overall perspective. Rex, an American opinion-leader in the area of colon cancer screening, reviewed the mounting evidence supporting the use of colonoscopy for this purpose. If colonoscopy is effective and cost effective as a screening option at age 50 years and also is endorsed by guidelines, Rex asks, then why look for reasons not to do a colonoscopy in symptomatic patients aged 50 years or older? The point is well taken. Van Rosendaal et al are correct in encouraging clinicians to be more discerning in their choice of investigations. However, the key question to be answered by the clinician, regardless of patient age, will always be: Is a colonoscopy going to be required before I am finished evaluating this patient? A clear answer is often forthcoming, when all issues pertinent to the individual patient's situation are considered. When a colonoscopy will ultimately be required anyway, a sigmoidoscopy should generally be avoided because it generates an added burden to resource strain rather than streamlining the evaluation.

It is important for clinicians to review critically the basis for their patterns of practice at regular intervals. In this regard, anyone who is thinking through or rethinking their approach to the evaluation of rectal bleeding will read with interest the contrasts of attitude (along with reviews of the pertinent literature supporting those differing viewpoints) that are presented by the van Rosendaal article and the accompanying editorial by Rex. 


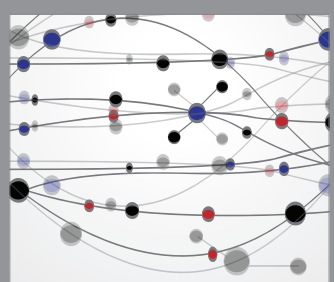

The Scientific World Journal
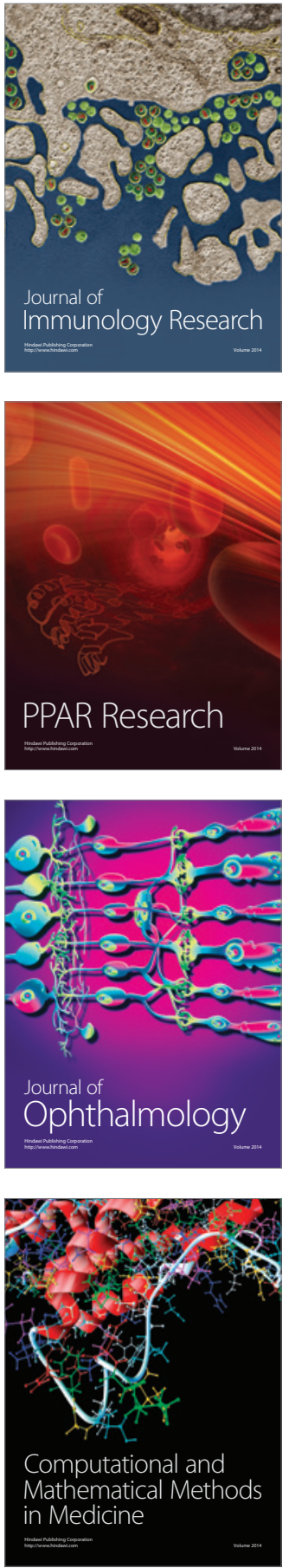

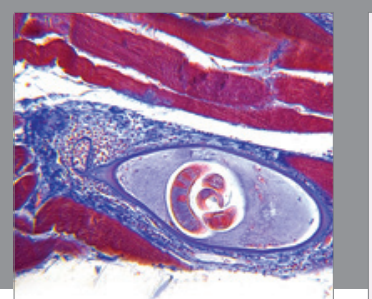

Gastroenterology Research and Practice

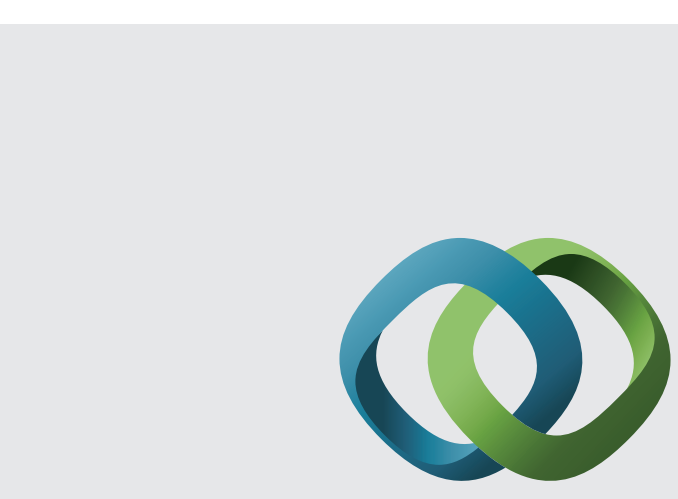

\section{Hindawi}

Submit your manuscripts at

http://www.hindawi.com
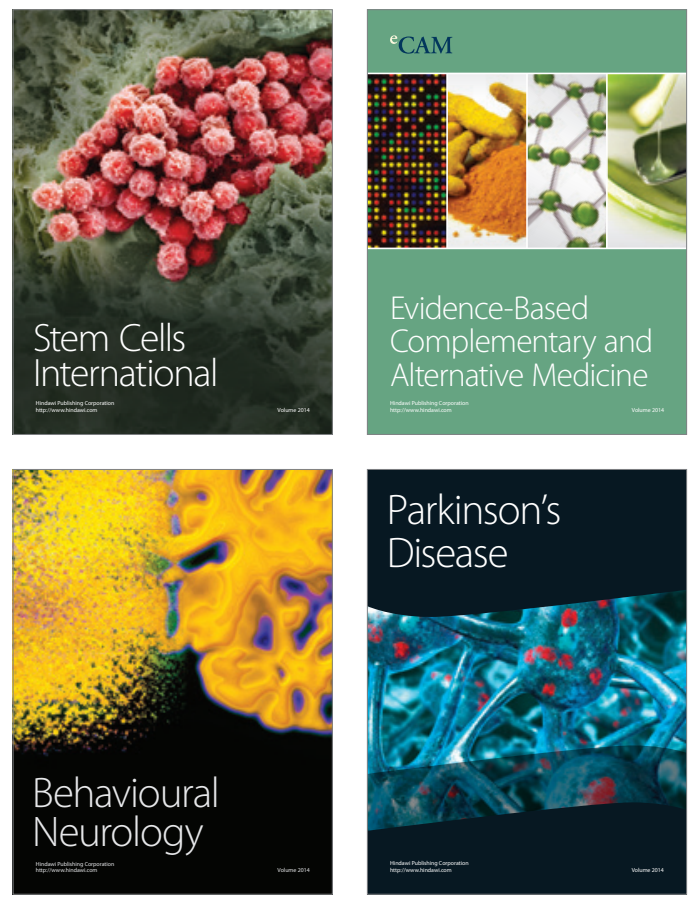
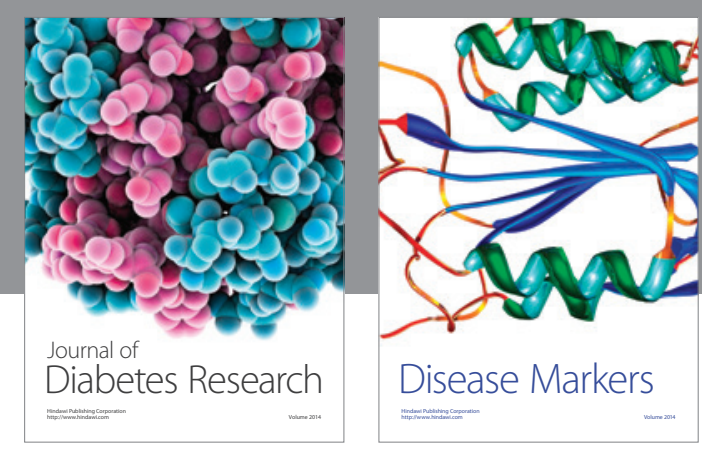

Disease Markers
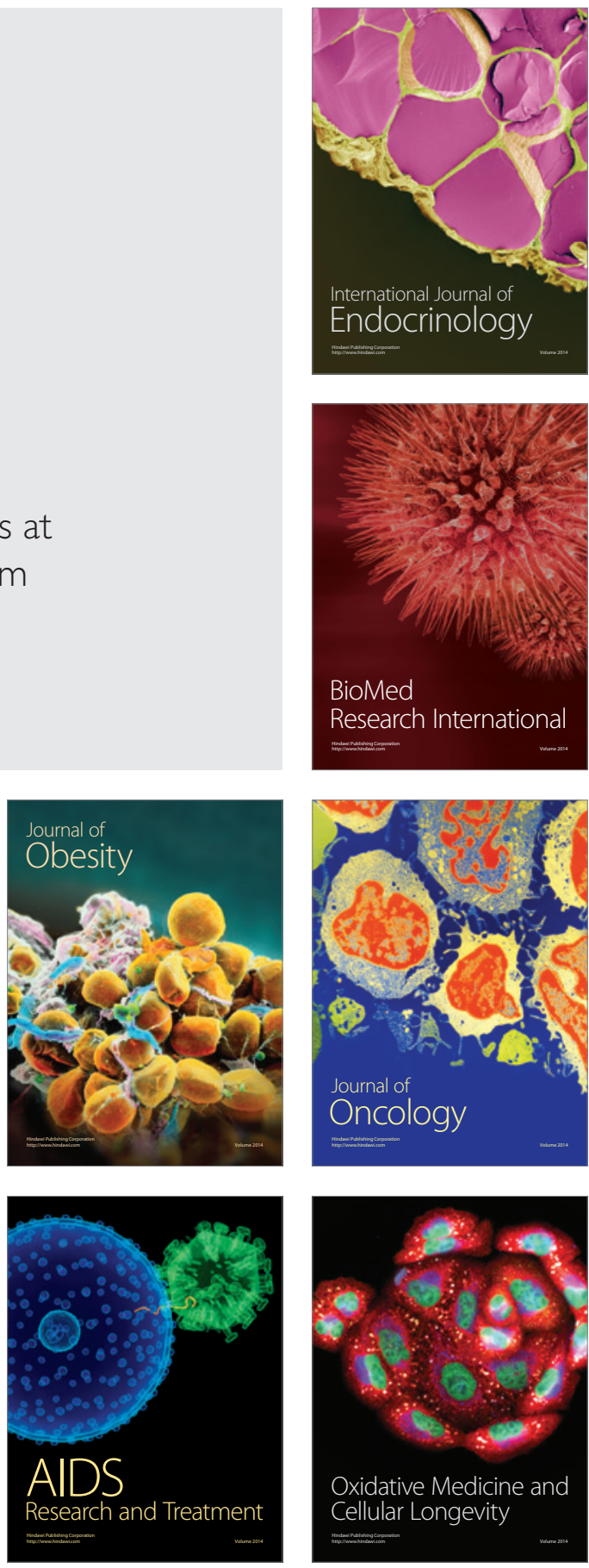